\title{
Explosive Welding of AI-MS Plates and its Interface Characterization
}

\author{
Bir Bahadur Sherpa ${ }^{1,2,3, a^{*}}$, Pal Dinesh Kumar ${ }^{2, b}$, Abhishek Upadhyay $^{2, \mathrm{c}}$ \\ Sandeep Kumar ${ }^{2, \mathrm{~d}}$, Arun Aggarwal ${ }^{2, \mathrm{e}}$, Sachin Tyagi ${ }^{1,3, \mathrm{f}}$ \\ ${ }^{1}$ Academy of Scientific and Innovative Research (AcSIR) Ghaziabad-201002, India \\ ${ }^{2}$ DRDO-Terminal Ballistics Research Laboratory (TBRL), Sector-30, Chandigarh 160030, India \\ ${ }^{3}$ CSIR-Central Scientific Instruments Organisation (CSIO), Sector-30, Chandigarh 160030, India \\ asherpa7419@gmail.com, bdineshpalb@yahoo.com, cabhiups007@gmail.com, \\ d sandeepk44@gmail.com, earun907@yahoo.com, 'sachintyagi.iitr@gmail.com
}

*Corresponding author: sherpa7419@gmail.com Tel: +91-1733-305062, Fax: +91-172-2657506

\section{Keywords: Explosive Welding, Impact Process, Hardness Value, Interface}

\begin{abstract}
Explosive welding is a solid state welding process in which two similar or different materials are claded with the help of explosive energy. The high pressure generated during the process helps to achieve the interatomic metallurgical bonding in the two materials. In this research work, $5 \mathrm{~mm}$ aluminum plate was cladded with $20 \mathrm{~mm}$ mild steel for plate length of $300 \mathrm{~mm}$ x100 $\mathrm{mm}$. Here parallel plate explosive welding set-up configuration using low VoD explosive consisting of mixture of Trimonite-1 and common salt was used. The interface joints were analyzed using optical inverted metallurgical microscope, SEM and Vickers Micro-hardness. It was observed that the value of micro-hardness at the interface was high as compared to the parent materials and decreased as we move away from the interface on both the sides. The optical and the SEM analysis showed straight morphology at most of the welded area. Al-MS plates were successfully welded using this low VoD explosive.
\end{abstract}

\section{Introduction}

Composite material with good corrosion resistant as well as bond strength is one of the prime needs of any industry for their respective work application. Explosive welding is a well known defined solid state weld process, where two plates are claded with the help of explosive energy in which flyer plate is accelerated towards the base plate and at the interface a very high pressure order of magnitude $10^{2}$ Mbar is generated followed by jet phenomenon[1]. Jet phenomenon is one of the important conditions for welding which occurs at the collision point in which it removes the oxide layer and provide clean mating surface free of contamination. This is attained by high pressure and kinetic energy deposited during the welding process[2]. Jet process helps atoms of two materials to meet at interatomic distance and form a strong metallurgical bond, where high temperature is obtained followed by rapid cooling in order of $10^{5} \mathrm{k} / \mathrm{s}[3]$. Beside this, for weld to occur the pressure should be sufficient high and for sufficient length of time to achieve the bond formation. In explosive welding, pressure generated exceeds the yield strength of both the materials and which act as fluid at the collision point. It is a critical joining process where different parameters such as collision velocity, flyer plate velocity, VoD of explosive plays a very important role in formation of good bond[2] [4]. Many researchers have worked on this process using different material combination with variable explosive properties [5] [6] [7]. Aluminum is a light and corrosion resistant material having vast application in the naval and oil industries. The challenge of joining comes due to difference in chemical, physical properties as well as low solubility of iron in aluminum. Different means have been used to join this combination such as magnetic pressure 
steam welding[8], diffusion bonding[9] ultrasonic welding[10] but all have some limitations and to circumvent this, explosive welding was adopted due to the advancement of joining any material combination with all size in a very few micro seconds. In this research work, aluminum is claded with mild steel and their behavior at interface is studied through micro-hardness \& micro-structural analysis by preparing specimen with standard dimensions.

\section{Material and methods}

In this present experiment, aluminum was claded with mild steel having dimensions of 300x100x5mm \& 300x100x20mm to produce single bimetallic materials. The systematic view of the explosive welding is shown in Fig. 1. Where the two plates kept parallel and separated by distance called stand-off. Low VoD explosive consisting of mixture of Trimonite-1 and common salt having VoD in the range of $1650-1800 \mathrm{~m} / \mathrm{s}$ was used. Aluminum as flyer plate was selected because of its light weight and superior corrosion resistant properties and mild steel as base plate due to its good tensile strength. The mechanical properties of the cladded material are shown in Table. 1 and the experimental parameters used are shown in Table.2. In this experiment, low VoD explosive was used to provide necessary energy for metallurgical bonding using parallel set-up arrangement[11]. The practical set-up for explosive welding is shown in Fig.2 (A), where the impact on the ground and on the plate after the explosion is shown in Fig.2 (B), which shows how much energy is generated during the welding process. The bimetallic plate formed after the process is shown in Fig.2 (C), where bonded plates were then subjected to micro-hardness \& micro structural examination, where in micro-hardness, the samples were prepared in the standard size and then examined the variation of hardness near the interface with the help of Vickers micro-hardness machine.

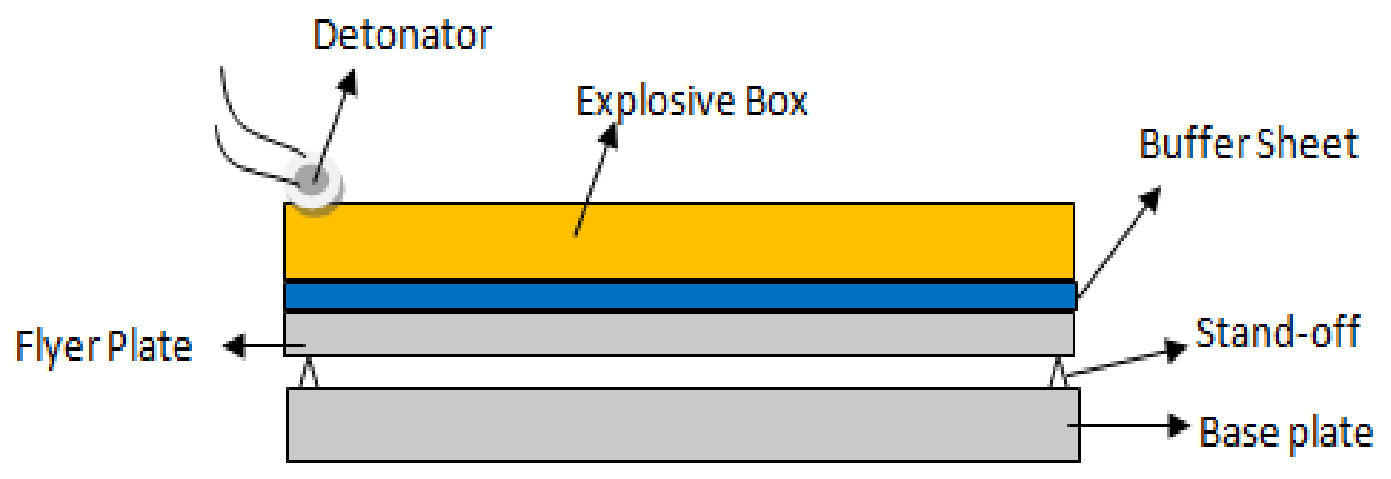

Fig.1. Systematic process diagram of explosive welding process 

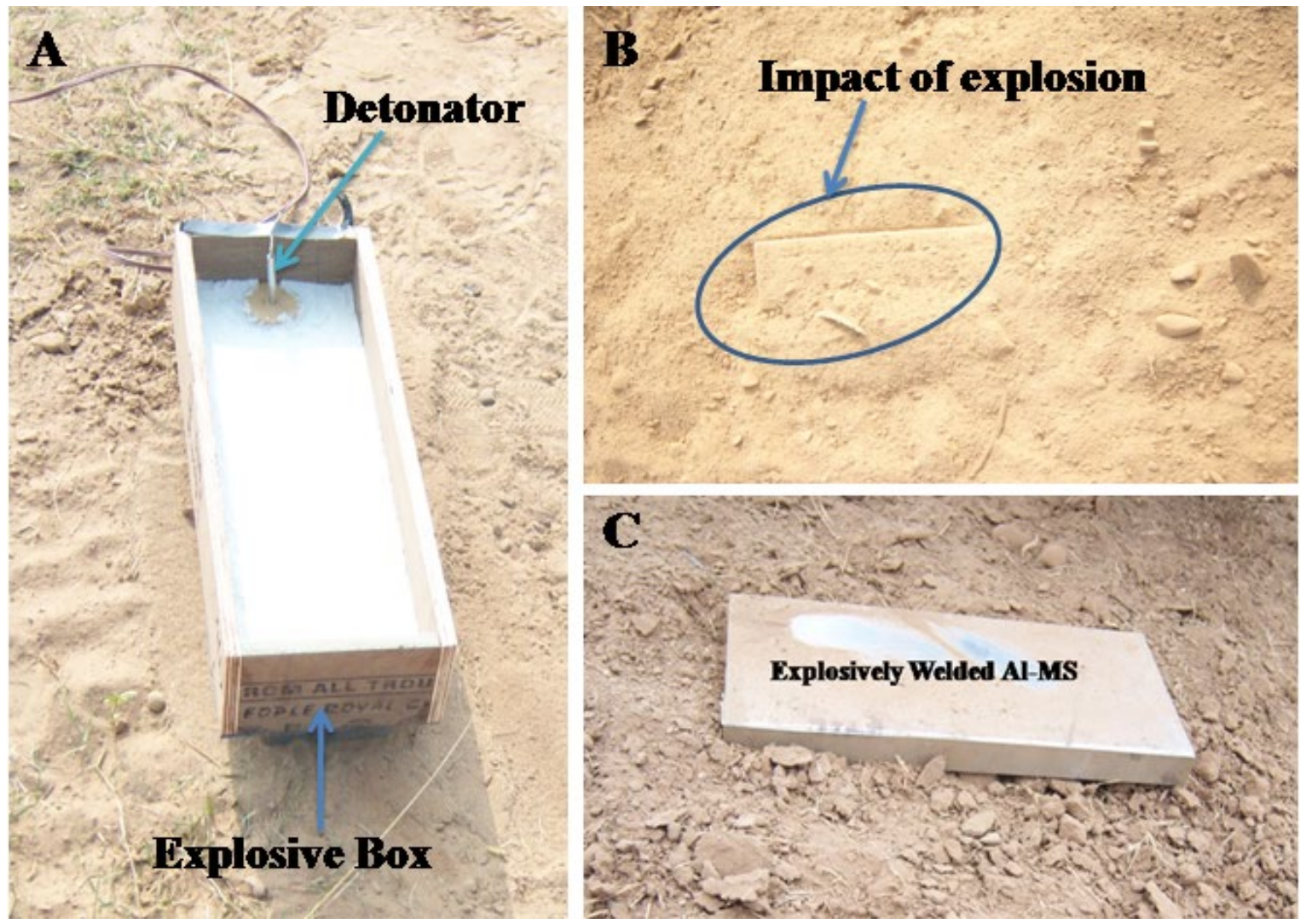

Fig.2. Overall set-up of explosive Welding A) Explosive box placed over plate B) Impact of explosion C) Bimetallic welded plates

Further for micro structural examination the samples were manually polished to $1 \mu \mathrm{m}$ finish. To study the internal structure, specimens were etched with $2 \%$ natal. This etched sample was analyzed in metallurgical optical microscope and to see the structural behavior near interface SEM was used. To check the transfer of elements during explosive welding dot mapping was performed. The successfully claded material was then subjected for further application.

Table.1 Mechanical Properties of Materials

\begin{tabular}{lll}
\hline Parameter & $\begin{array}{l}\text { Aluminum (Al) } \\
\text { Pure }\end{array}$ & $\begin{array}{l}\text { Mild steel (MS) } \\
\mathbf{1 0 2 0}\end{array}$ \\
\hline Hardness Value in (measured & 41 & 160 \\
Vickers's) & 928 & 1789 \\
Melting Point (Kelvin) & 0.0027 & 0.00786 \\
Density (Kg/cm $\left.{ }^{3}\right)$ & 90 & 340 \\
UTS (MPa) & 235 & 51.1 \\
Thermal conductivity (W/mK) & 904 & 486 \\
Specific Heat (J/Kg K) & & \\
\hline
\end{tabular}


Tabel.2 Experimental parameters

\begin{tabular}{ll}
\hline Parameter & Value \\
\hline Flyer Plate with Dimension $(\mathrm{mm})$ & Pure Aluminum (300x100x5) \\
Base Plate with Dimension $(\mathrm{mm})$ & Mild Steel 1020(300x100x19) \\
Explosive & Trimonite with Salt Mixture \\
Loading Ratio & 1.2 \\
Stand-off Distance $(\mathrm{mm})$ & 6 \\
Velocity of Detonation $(\mathrm{m} / \mathrm{s})$ & $1550-1650$ \\
\hline
\end{tabular}

\section{Results and Discussion}

The bonded joints were examined by different equipment such as Vickers hardness, optical microscope, SEM. The morphology of the interface was straight with slight wavy at some interval as observed in both optical (Fig.3) and SEM images (Fig.4). Further to analyze the transfer of elements at the interface dot mapping (Fig.5) was done. Where, a sharp and clear image of elements at the interface confirmed good bonding. Micro-hardness indentations of first two points from either side along with interface point were plotted against hardness Vs distances are shown in Fig.6. The average hardness value of the mild steel was $157 \mathrm{HV}$ and that of aluminum was $41 \mathrm{HV}$ initially. It was observed that the hardness value at the interface had increased to $210 \mathrm{HV}$ as compared to adjacent material. The hardness value was increasing towards interface and stable after some distance away from interface. This similar increase in hardness was also reported by Mudali et al. [12] for titanium \& stainless steel and by Abhishek et al. [6] for SS304 \& AA6061.The increase in hardness is mainly due to grain dislocation pileup from shock hardening during explosive welding process \& can also be observed in optical image as shown in Fig.3.Further the grain boundaries containing ferrite \& pearlite were observed by adding etchant of Nital (2\%).

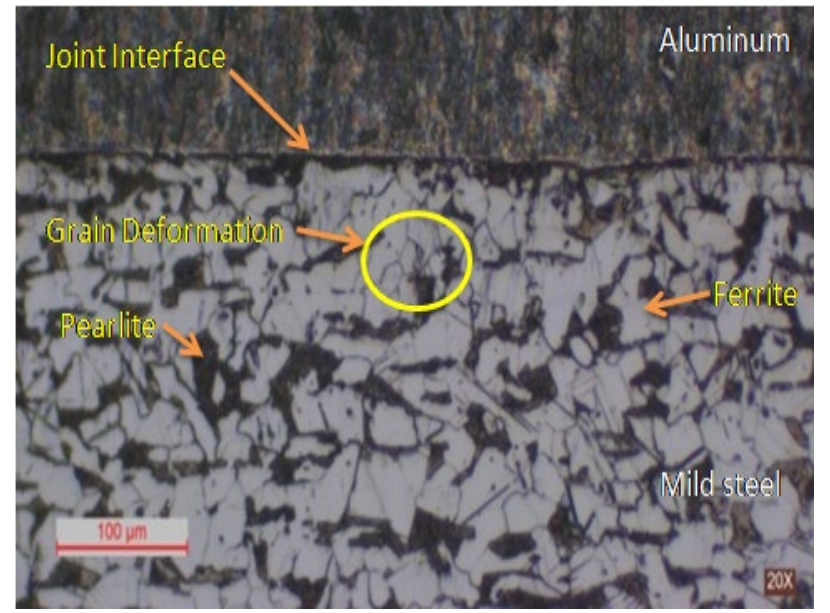

Fig.3. Optical structure of welded Al-MS plates

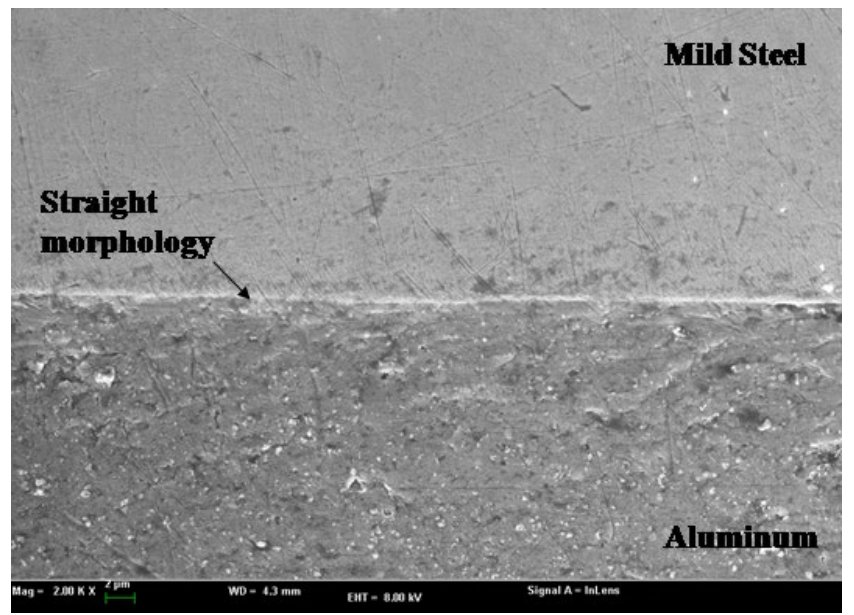

Fig.4. SEM image for bonded Al-MS interface 

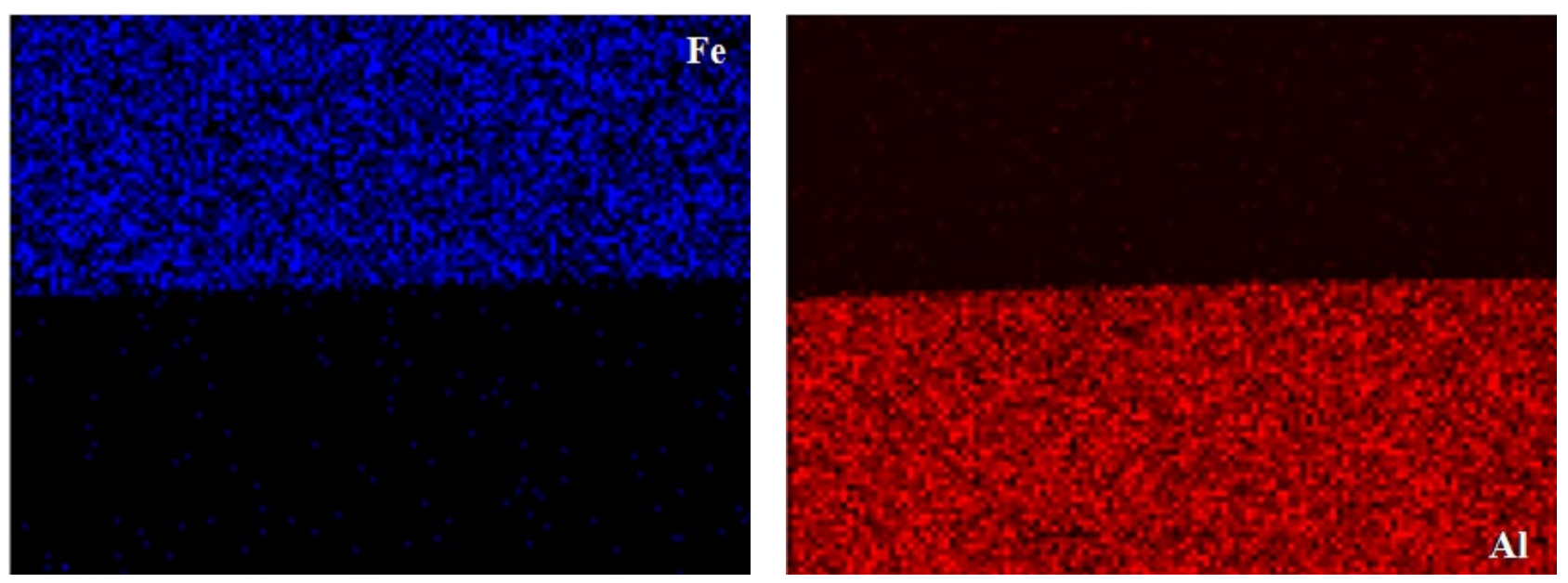

Fig.5. Dot mapping of the bonded Al-MS interface

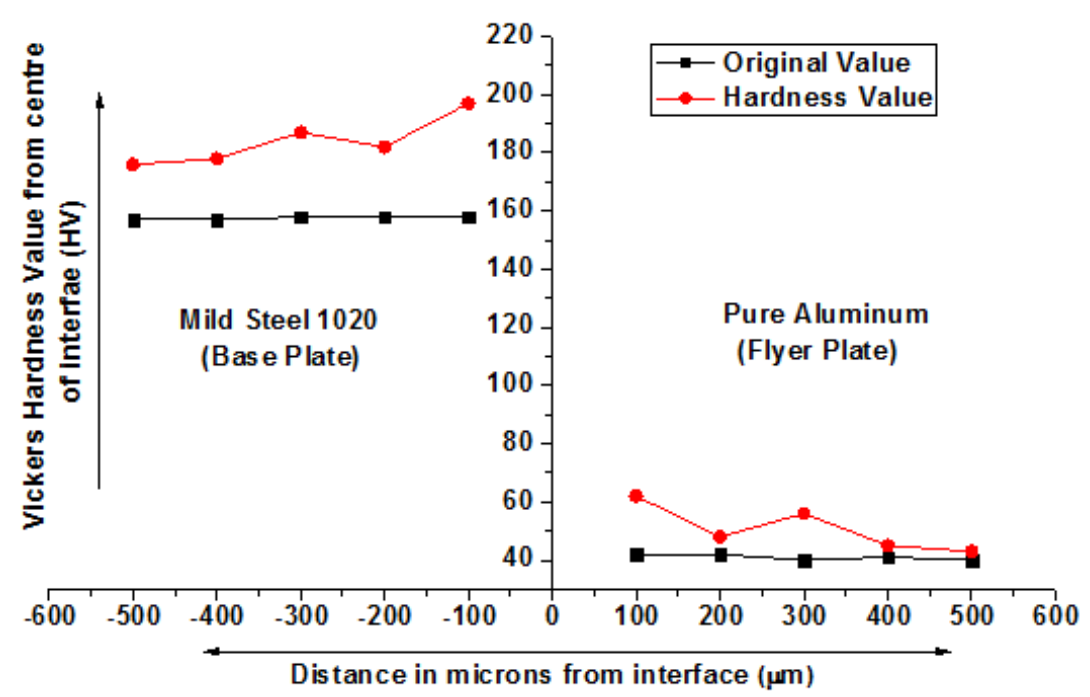

Fig.6. Micro-Hardness profile across interface of aluminum \& mild steel

\section{Conclusion}

Pure aluminum and mild steel 1020 bimetallic plate were claded successfully. For joining these two incompatible materials, low velocity of detonation $(\mathrm{VoD})$ explosive having $\mathrm{VoD}$ in range of 1650 $1650 \mathrm{~m} / \mathrm{s}$ was applied. Microhardness examination showed an increase in hardness value towards the interface as noticed from both the materials end. This increase in hardness can also be correlated with the grain deformation as observed in optical microscope images at the interface. In microstructural examination we observed straight morphology at the weld interface of the welded bimetallic plates.

\section{Acknowledgements}

The support from Terminal Ballistics Research Laboratory is highly acknowledged. Authors are very thankful to Dr. Manjit Singh, Director, TBRL Chandigarh and all the scientists, M.T section \& workshop of TBRL for their valuable support.

\section{Reference}

1. Bernard Crossland, Oxford Series of Advanced Manufacturing 2 1982, p. 233. 
2. AA Akbari Mousavi and STS Al-Hassani, Journal of the Mechanics and Physics of Solids 2005, vol. 53, pp. 2501-2528.

3. Tadeusz Zdzislaw Blazynski: Explosive welding, forming and compaction. (Springer Science \& Business Media, 2012).

4. Bir Bahadur Sherpa, Pal Dinesh Kumar, Abishek Upadhyay, Uma Batra and Arun Agarwal, Advances in Applied Physical and Chemical Sciences-A Sustainable Approach 2014, pp. 33-39.

5. K Raghukandan, Journal of Materials Processing Technology 2003, vol. 139, pp. 573-577.

6. Abhishek Upadhyay, Bir Bahadur Sherpa, Sandeep Kumar, Niraj Srivastav, Pal Dinesh Kumar and Arun Agarwal, In Materials Science Forum, (Trans Tech Publ: 2015), pp 261-264.

https://doi.org/10.4028/www.scientific.net/msf.830-831.261

7. $\quad$ SAA Akbari Mousavi and P Farhadi Sartangi, Materials \& Design 2009, vol. 30, pp. 459-468.

8. Kwang-Jin Lee, Shinji Kumai, Takashi Arai and Tomokatsu Aizawa, Materials Science and Engineering: A 2007, vol. 471, pp. 95-101.

9. PS Gawde, R Kishore, AL Pappachan, GB Kale and GK Dey, Transactions of the Indian Institute of Metals 2010, vol. 63, pp. 853-857. https://doi.org/10.1007/s12666-010-0130-x

10. N Mohan Raj, LA Kumaraswamidhas, Pavan Kumar Nalajam and S Arungalai Vendan, Transactions of the Indian Institute of Metals 2018, vol. 71, pp. 107-116.

https://doi.org/10.1007/s12666-017-1140-8

11. Bir Bahadur Sherpa, Abhishek Upadhyay, Sandeep Kumar, Pal Dinesh Kumar and Arun Agarwal, Materials Today: Proceedings 2017, vol. 4, pp. 1260-1267.

12. U Kamachi Mudali, BM Ananda Rao, K Shanmugam, R Natarajan and Baldev Raj, Journal of Nuclear Materials 2003, vol. 321, pp. 40-48. 